\title{
Grain yield and competitive ability against weeds in modern and heritage common wheat cultivars are differently influenced by sowing density
}

\author{
Mariateresa Lazzaro, ${ }^{1}$ Ambrogio Costanzo, ${ }^{1,2}$ Dalia Hosam Farag, ${ }^{3}$ Paolo Bàrberi ${ }^{1}$ \\ ${ }^{1}$ Institute of Life Sciences, Scuola Superiore Sant'Anna, Pisa, Italy; ${ }^{2}$ The Organic Research Centre, \\ Hamstead Marshall, Newbury, UK; ${ }^{3}$ Mediterranean Agronomic Institute of Chania, Alsyllio Agrokepio, \\ Crete, Greece
}

\begin{abstract}
Sowing density can have a strong impact on crop stand development during wheat growing cycle. In organic and low-input agriculture, and therefore with minimum or nil use of chemical herbicides, increased sowing density is expected to affect not only grain yield but also weed suppression. In this study we tested, under Mediterranean conditions, six common wheat cultivars (three modern and three heritage) and two three-component mixtures (arranged by combining the three modern or the three heritage cultivars). The different crop stands were tested at sowing densities of 250 (low) and 400 (high, similar to standard sowing density used by local farmers) viable seeds $\mathrm{m}^{-2}$ for two growing seasons. We did not detect a significant effect of crop stand diversity (single cultivars $v s$ mixtures) on grain yield and weed suppression. Differences were ascribed to type of cultivars used (heritage $v s$ modern). Compared to high sowing density, in modern cultivars grain yield did not decrease significantly with low sowing density, whereas in heritage cultivars it increased by $15.6 \%$, possibly also because of $21.5 \%$ lower plant lodging. Weed biomass increased with low sowing density both in heritage and modern cultivar crop stand types. However, heritage crop stands
\end{abstract}

Correspondence: Mariateresa Lazzaro, Institute of Life Sciences, Scuola Superiore Sant'Anna, Piazza Martiri della Libertà 33, 56127 Pisa, Italy.

E-mail: mariateresa.lazzaro@santannapisa.it

Key words: Cultural weed management; Low-input agriculture; Organic agriculture; Trait; Weed suppression.

Acknowledgements: we thank Giacomo Nardi for technical assistance with the field experiments management and the local gene bank Terre Regionali Toscane (http://germoplasma.arsia.toscana.it/) for providing the seed samples of the heritage cultivars.

Received for publication: 21 December 2016.

Revision received: 7 May 2017.

Accepted for publication: 10 May 2017.

(C) Copyright M. Lazzaro et al., 2017

Licensee PAGEPress, Italy

Italian Journal of Agronomy 2017; 12:901

doi:10.4081/ija.2017.901

This article is distributed under the terms of the Creative Commons Attribution Noncommercial License (by-nc 4.0) which permits any noncommercial use, distribution, and reproduction in any medium, provided the original author(s) and source are credited. had, on average, a lower weed biomass (56\%) than modern crop stands. Moreover, weed biomass in heritage crop stands at low density $\left(6.82 \pm 1.50 \mathrm{~g} \mathrm{~m}^{-2}\right)$ was lower than that of modern cultivars at the same sowing density $\left(15.54 \pm 3.35 \mathrm{~g} \mathrm{~m}^{-2}\right)$, confirming the higher suppressive potential of the former. We can conclude that lower sowing density can be advisable when using heritage crop stands as it keeps productivity while decreasing plant lodging and maintaining weeds under control.

\section{Introduction}

Sowing density and, consequently, crop density is an important factor in determining the competitive ability of cereals against weeds (Doll et al., 1995; Kristensen et al., 2008) as well as the expression of their grain yield potential (Beavers et al., 2008; Beres et al., 2016; Li et al., 2016). The crop density to grain yield relationship is not directly proportional. Grain yield depends on environmental (E) and genetic (G) factors, as well as on the $\mathrm{G} \times \mathrm{E}$ interaction. In other words, yield is affected by trait plasticity, i.e. the compensatory ability of the crop to sustain yield by changing yield components. Sadras et al. (2009) reported how breeders face this issue in terms of difficulties to produce cultivars adapted to broad geographical areas due to $\mathrm{G} \times \mathrm{E}$ interaction, whereas ecologists deal with the same type of problem from the perspective of phenotypic plasticity. The original idea of plant phenotypic plasticity goes back to Bradshaw (1965) who defined it as the amount by which the expressions of individual characteristics of a genotype are changed by different environments. Wheat yield components that participate in the expression of grain yield (fertile tillers $\mathrm{m}^{-2}$, spikes plant ${ }^{-1}$, kernels spike ${ }^{-1}$, and kernel weight) are interdependent and can compensate for one another to stabilise yield as environmental conditions change (Reynolds et al., 1996).

Crop density has a strong influence on weed suppression because it is linked with the expression of key traits for this agroecosystem service like ground cover and above ground biomass accumulation (Andrew et al., 2015). For example in Doll et al. (1995), weed biomass was shown to be strongly dependent on crop density. In that experiment crop density affected more weed biomass than grain yield. Recent studies showed the potential increase of weed suppression ability in wheat by the combination of increased crop density and spatial uniformity (Olsen et al., 2006; Kristensen et al., 2008). Andrew and Storkey (2016) used simulation models to investigate the effects of sowing date and cultivar choice in relation to sowing density. This study showed that delayed sowing density, competitive cultivars and increased crop density work well in combination for increasing crop competitive ability against weeds. Beavers et al. (2008) suggested that seed density should be increased under organic and low-input farming for increasing crop competitive ability while maintaining 
grain yield and quality. Usually, with higher crop density weeds are suppressed better, due to lower inter-specific competition, although intraspecific competition within the wheat stand increases. If crop density is too high, this can result in lower harvest index, fewer kernels per spike, and lower kernel weight (Puckridge and Donald, 1967). At lower crop density, plants may produce more tillers resulting in similar numbers of spikes $\mathrm{m}^{-2}$ as it would be achieved with higher sowing density (Freeze and Bacon, 1990). In addition, Whaley et al. (2000) reported that in some cases low density prevented lodging of the crop, without an increase or even with a decrease of weed biomass, resulting in increased harvest index. These examples show that dense planting does not necessarily increase wheat grain yield.

Cultivar type is another important aspect that influences weed suppression. In several studies, heritage cultivars resulted more competitive against weeds than modern cultivars because of higher plant height, biomass accumulation, tillering and soil cover (Korres and Froud-Williams, 2002; Mason et al., 2007; Hoad et al., 2012; Ruisi et al., 2015).

Higher diversity in the crop stand can have as well an effect on weed suppression (Kaut et al., 2009) and on intraspecific competition at crop stand level (Fang et al., 2011). To date, the effect of cultivar mixtures on weed suppression has not been studied in depth despite being an interesting aspect to investigate in the framework of integrated weed management (Kaut et al., 2009). We tested, under Mediterranean conditions, six cultivars (three modern and three heritage) and two three-component mixtures (arranged by combining the three modern or the three heritage cultivars) at low (250) or high (400 viable seeds $\mathrm{m}^{-2}$ ) sowing density for two growing seasons. The high sowing density roughly corresponds to the standard one used by local farmers. The experiment was conducted in simulated organic conditions with no use of herbicides and fungicides, under natural weed pressure.

With this experiment, we tested the hypothesis that the effect of lower sowing density on grain yield might change with type of cultivars (heritage vs modern) and crop stand diversity (cultivar $v s$ mixture).

\section{Materials and methods}

\section{Study site and experimental design}

A field trial was replicated across two growing seasons (2013/14 and 2014/15). The experiment was carried out at the Interdepartmental Centre for Agri-environmental Research

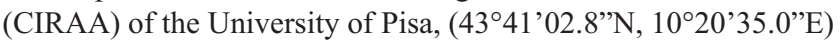
on an alkaline loamy soil (Table 1$)$. No herbicide, fungicide and mineral fertiliser was applied for simulating the typical conditions of organic management. The organic fertiliser NUTEX (i.e. pelleted manure with $3 \% \mathrm{~N}$ and $3 \% \mathrm{P}_{2} \mathrm{O}_{5}$ ) was incorporated into the soil before sowing in the dose of $1 \mathrm{tha}^{-1}$. In the first year, the experiment was sown as wheat re-crop preceded by a five-year lucerne (Medicago sativa L.) ley. In the second year, wheat followed a pigeon bean (Vicia faba L. var. minor) crop. Seedbed was prepared by ploughing at $25 \mathrm{~cm}$ depth and subsequent disc harrowing at 7 to $10 \mathrm{~cm}$ depth.

Wheat was sown on 14 November 2013 and 30 October 2014. The experiment was harvested on 2 July 2014 and 30 June 2015. Total rainfall from sowing to harvest was $986 \mathrm{~mm}$ in the first year and $891 \mathrm{~mm}$ in the second. The minimum temperature ranged from 1 to $16^{\circ} \mathrm{C}$ in the first year and from 0.7 to $11^{\circ} \mathrm{C}$ in the second. The maximum temperature ranged from 12 to $29^{\circ} \mathrm{C}$ and from 11 to $30^{\circ} \mathrm{C}$ in the first and second year respectively.

The experiment was organised in a randomised complete block design with three replicates. Wheat was mechanically sown in 1.5 $\times 7 \mathrm{~m}$ plots in $15 \mathrm{~cm}$ spaced rows. Six Italian varieties (Table 2) of commmon wheat (Triticum aestivum L.) were arranged in the 16 treatments (Table 3).

The experiment addressed three factors: i) sowing density (DEN), comparing a high density (HIGH) of 400 seeds $\mathrm{m}^{-2}$ to a low density (LOW) of 250 seeds $\mathrm{m}^{-2}$; ii) crop stand diversity (DIV), comparing single stands of the six cultivars (VAR) with mixtures of the three heritage or of the three modern cultivars (MIX); iii) cultivar type (TYP), comparing heritage (HER) to modern (MOD) cultivars (Table 3).

The choice to not mix cultivars of the two types was taken to obtain a uniform end-use quality, and, as such, test mixtures more easily usable either by farmers and millers.

Seeds of the heritage cultivars Autonomia A and Gentil Rosso were provided by Terre Regionali Toscane (Tuscany Region local germplasm seed-bank), while seeds of cv. Verna were provided by the organic farm Il Cerreto [Pomarance (PI), Italy]. All modern cultivars were provided by the breeding companies that commercialise them. Cultivars were selected based on their differing growth traits: cv. Autonomia A, Gentil Rosso and Verna are tall $(111-135 \mathrm{~cm})$ heritage varieties whereas cv. Albachiara, Blasco and Bolero are relatively dwarf $(61-72 \mathrm{~cm})$ modern varieties.

\section{Data collection}

Yield and yield components (Table 4) were measured at physiological maturity (BBCH GS92) (Meier et al., 2009). Crop lodging percentage was visually assessed in each plot just before harvest. Above ground weed biomass was collected three times per year: at the end of winter (BBCH GS 30), in spring (BBCH GS 60/69) and at crop physiological maturity (BBCH GS 92). Biomass sampling was performed in one quadrat per plot of $25 \times 30 \mathrm{~cm}$ for the first sampling, $45 \times 50 \mathrm{~cm}$ for the second, and $1 \times 1 \mathrm{~m}$ for the third sampling. Dry biomass weights were obtained by oven-drying samples at $60^{\circ} \mathrm{C}$ for the first sampling and $100^{\circ} \mathrm{C}$ for the other samplings until constant weight. Crop biomass, final crop height and leaf area index (LAI) were measured as traits linked to weed suppression possibly affected by sowing density (Table 5).

Table 1. Soil properties of the experimental fields used in 2013/14 and 2014/15.

\begin{tabular}{cccccccccc} 
& pH & $\begin{array}{c}\text { Conductivity } \\
(\text { micros })\end{array}$ & $\begin{array}{c}\text { CSC } \\
\left(\mathrm{meq}^{\left.100 \mathrm{~g}^{-1}\right)}\right.\end{array}$ & $\begin{array}{c}\text { Total N*} \\
\left(\mathrm{mg} \mathrm{kg}^{-1}\right)\end{array}$ & $\begin{array}{c}\text { Organic matter } \\
(\%)\end{array}$ & $\begin{array}{c}\mathrm{p}^{*} \\
(\mathrm{ppm})\end{array}$ & $\begin{array}{c}\text { Clay } \\
(\%)\end{array}$ & $\begin{array}{c}\text { Silt } \\
(\%)\end{array}$ & $\begin{array}{c}\text { Sand } \\
(\%)\end{array}$ \\
\hline $2013 / 14$ & 8.03 & 101.17 & 2.97 & 1.43 & 2.03 & 6.32 & 17.51 & 47.54 & 34.95 \\
$2014 / 15$ & 8.15 & 85.20 & 2.22 & 1.77 & 2.64 & 7.39 & 27.40 & 38.14 & 34.46 \\
\hline
\end{tabular}

CSC, cation-exchange capacity; N, nitrogen; P, phosphorus. *Kjeldahl method; ${ }^{\circ}$ Walkley-Black method; ${ }^{\circledR}$ Olsen method. 


\section{Data analysis}

All statistical analyses were conducted using R environment for statistical computing, version 3.3.1 (R Core Team, 2016). A cumulative analysis of variance (ANOVA) for each explanatory variable was performed using a mixed effect model. The model was formulated as:

$\mathrm{Y}_{\mathrm{ijkl}}=\mu+\mathrm{DEN}_{\mathrm{i}}+\mathrm{TYP}_{\mathrm{j}}+\mathrm{DIV}_{\mathrm{k}}+\left(\mathrm{DEN}: T Y P_{\mathrm{ij}}+(\mathrm{DEN}: \mathrm{DIV})_{\mathrm{ik}}+\right.$ $(\text { TYP:DIV })_{\mathrm{jk}}+(\text { DEN:TYP:DIV })_{\mathrm{ijk}}+$ YEAR/BLOCK/CV $1+\varepsilon_{\mathrm{ijkl}}$

Eq. 1
Table 2. Wheat cultivars used in the experiment.

\begin{tabular}{lcl} 
& Wheat cultivar & Type of cultivar \\
1 & Albachiara & Modern \\
2 & Blasco & Modern \\
\hline 3 & Bolero & Modern \\
4 & Gentil Rosso & Heritage \\
\hline 5 & Autonomia A & Heritage \\
6 & Verna & Heritage \\
\hline
\end{tabular}

Table 3. Field experiment treatments and codes.

\begin{tabular}{lllll} 
Code & Cultivar(s) & Sowing density & Crop stand diversity & Cultivar(s) type \\
ALB & Albachiara & High & Cultivar & Modern \\
BLA & Blasco & High & Cultivar & Modern \\
\hline BOL & Bolero & High & Cultivar & Modern \\
GRO & Gentil Rosso & High & Cultivar & Heritage \\
\hline AUT & Autonomia A & High & Cultivar & Heritage \\
VER & Verna & High & Cultivar & Heritage \\
\hline MX_MOD & Albachiara+Blasco+Bolero & High & Mixture & Modern \\
MX_HER & Autonomia A+Gentil Rosso+Verna & High & Mixture & Heritage \\
\hline ALB & Albachiara & Low & Cultivar & Modern \\
BLA & Blasco & Low & Cultivar & Cultivar \\
\hline BOL & Bolero & Low & Cultivar & Modern \\
GRO & Gentil Rosso & Low & Cultivar & Modern \\
\hline AUT & Autonomia A & Low & Cultivar & Heritage \\
VER & Verna & Low & Mixture & Heritage \\
\hline MX_MOD & Albachiara+Blasco+Bolero & Low & Mixture & Heritage \\
MX_HER & Autonomia A+Gentil Rosso+Verna & Low & & Modern \\
\hline
\end{tabular}

Table 4. Yield and yield components measurements.

\begin{tabular}{|c|c|c|}
\hline Character & Sampling & Measurement \\
\hline Grain yield & One $1 \times 1 \mathrm{~m}$ quadrat & $100^{\circ} \mathrm{C}$ Oven-drying until constant weight \\
\hline Number of seedings $\mathrm{m}^{-2}$ & Three $25 \times 30$ quadrats one month after sowing & Number of seedlings $\mathrm{m}^{-2}$ \\
\hline Number of tillers plant ${ }^{-1}$ & Three $25 \times 30$ quadrats for tillers' number & Number of tillers $\mathrm{m}^{-2} /$ number of seedlings $\mathrm{m}^{-2}$ \\
\hline Number of fertile tillers plant ${ }^{-1}$ & One $1 \times 1 \mathrm{~m}$ quadrats for spike number & Number of spikes $\mathrm{m}^{-2} /$ number of seedlings $\mathrm{m}^{-2}$ \\
\hline Number of seeds spike ${ }^{-1}$ & 10 random spikes plot ${ }^{-1}$ & Count of seeds spike ${ }^{-1}$ \\
\hline Number of fertile spikelets spike ${ }^{-1}$ & 10 random spikes plot ${ }^{-1}$ & Count of fertile spikelets spike ${ }^{-1}$ \\
\hline Thousand kernel weight & 3 samples of 100 seeds from the combine harvested grain & Weight (g) \\
\hline
\end{tabular}

Table 5. Traits related to weed suppression and details of sampling and measurement.

\begin{tabular}{|c|c|c|}
\hline Trait & Sample & Measurement \\
\hline Crop biomass & $25 \times 30 \mathrm{~cm}$ quadrat at end of tillering & Oven dried above ground biomass until constant weight ( $\mathrm{g}$ ) \\
\hline Crop biomass & $45 \times 50 \mathrm{~cm}$ quadrat at flowering & Oven dried above ground biomass until constant weight (g) \\
\hline Crop biomass & $1 \times 1 \mathrm{~m}$ quadrat at harvest & Oven dried straw biomass until constant weight (g) \\
\hline Leaf area index & In April and May, average of three readings per plot & $\begin{array}{l}\text { Indirect measure with a SunScan Canopy analyser } \\
\text { (Delta-T Devices Ltd, Cambridge, UK) }\end{array}$ \\
\hline Plant height & 10 random plant per plot at harvest & Cm from the base of the culm to the end of the spike (excluding awns) \\
\hline
\end{tabular}


where $Y_{i j k l}$ is the variable value for the sowing density $i\left(D E N_{i}\right)$, type of cultivar in the crop stand $\mathrm{j}\left(\mathrm{TYP}_{\mathrm{j}}\right)$, crop stand diversity $\mathrm{k}$ $\left(D_{\mathrm{k}}\right)$. DEN:TYP, DEN:DIV and TYP:DIV represent the first order interactions factors, whereas DEN:TYP:DIV represents the second order interaction among the three factors. The factor YEAR/BLOCK/CV nests each cultivar in each block in each year.

In the model, $\mu$ represents the grand mean and $\varepsilon_{\mathrm{ijkl}}$ is the residual error. The model was run with DEN, TYP, DIV and the related interactions as fixed effects. The grouping factor YEAR/BLOCK/CV was used as random effect. Count data were analysed with a generalised linear mixed model using the Poisson distribution and continuous variables were analysed with linear mixed model. Both analyses were run by using R/lme4 (Bates et al., 2015). When the requirements for the linear model for continuous variables were not met, we used a generalised linear mixed model with Gaussian distribution and logarithm link function. A backward selection was applied, using the function step() in R/lmerTest (Kuznetsova et al., 2016) for the linear mixed models and dredge() in R/MuMIn (Barton, 2016) for the generalised linear mixed model in order to identify the significant factors and interactions. Non-significant fixed factors were retained in the final model when they were part of a significant interaction. Likelihood ratio tests (LRT) of the final model for each variable are presented for showing the significance of the retained fixed effects and interactions. Appropriate post-hoc tests were run in $\mathrm{R} /$ lsmeans (Lenth, 2016) for each final model according to the fixed effects kept in the model.

\section{Results}

\section{Effect of sowing density on tiller number, plant and spike density}

Sowing density affected tiller number, plant and spike density along the growing season. In low density, seedlings were planned $37.5 \%$ lower compared to high density. The average actual difference in terms of emerged seedlings between sowing densities was $34.5 \%$, not distinguishable from what planned (t-test $95 \%$ confidence interval $[29.8,39.2]$ ). This difference was not affected by type or diversity of the crop stand, but the difference decreased significantly to $4.6 \%$ at the end of tillering phase (t-test $95 \%$ confidence interval $[0.0,12.3])$. However, at harvest, spike number was $13.4 \%$ lower under low density (t-test $95 \%$ confidence interval $[8.3,18.4])$. The number of tillers per plant was $49.2 \%$ higher under low density ( $2.97 \pm 0.26$ vs $1.99 \pm 0.26$ at high density) (Table 6). We detected a significantly higher tiller number per plant in heritage cultivars $(2.76 \pm 0.27$ vs $2.21 \pm 0.27$ in modern cultivars) (Table $6)$. The number of fertile tillers per plant was higher at low density (1.26 \pm 0.18 vs $0.94 \pm 0.18$ at high density) (Table 6). In contrast, there was no significant effect of cultivar type on number of spikes per plant. No effect of diversity was detectable for these traits. Neither the number of tillers per plant nor number of spikes per plant levelled completely the starting plant density condition.

\section{Yield and yield components}

Grain yield was differently influenced by sowing density in the two types of cultivars (significant density by type interaction) (Table 7). We did not detect any effect of crop stand diversity on yield. Modern cultivars produced more than heritage cultivars with a negligible difference between the two sowing densities (Figure 1).

Heritage cultivars had a higher grain yield at low density (Figure 1).

Given the lower number of spikes $\mathrm{m}^{-2}$ at low density, to explain these results we need to look at the data on yield components. The number of seeds spike ${ }^{-1}$ was affected by sowing density (Table 8 ). The interaction DEN:DIV was statistically significant even if the difference between mixture and variety was not significant neither at high nor low density $(\mathrm{P}=0.008)$ (Table 8$)$. The number of seeds spike $^{-1}$ was on average $12 \%$ higher at low density (Figure 2 ).

The number of seeds spike ${ }^{-1}$ increased at low density because of an increase in the number of fertile spikelets spike ${ }^{-1}$ (Table 8 and Figure 3).

Table 6. Likelihood ratio test for fixed factors and interactions in the retained model for number of tillers and fertile tillers per plant.

\begin{tabular}{|c|c|c|c|}
\hline & Factor & $x^{2}$ & $\mathbf{P}$ \\
\hline Number of tillers plant ${ }^{-1}$ & $\begin{array}{l}\text { DEN } \\
\text { TYP }\end{array}$ & $\begin{array}{l}39.17 \\
10.43\end{array}$ & $\begin{array}{c}0.000^{* * *} \\
0.001^{* *}\end{array}$ \\
\hline Number of fertile tillers plant ${ }^{-1}$ & DEN & 41.82 & $0.000 * * *$ \\
\hline
\end{tabular}

DEN, sowing density; TYP, type of cultivars. ${ }^{*} \mathrm{P}<0.01 ; * * \mathrm{P}<0.001$.

Table 7. Likelihood ratio test for fixed factors and interactions in the retained model for grain yield.

\begin{tabular}{lcc} 
Factor & $\chi^{2}$ & $\mathrm{P}$ \\
DEN & 9.16 & $0.002^{* *}$ \\
TYP & 4.51 & $0.03^{*}$ \\
\hline DEN:TYP & 11.23 & $0.0008^{* * *}$ \\
\hline
\end{tabular}

DEN, sowing density; TYP, type of cultivars; DEN:TYP, density by type interaction. ${ }^{* \mathrm{P}}<0.05 ;{ }^{*} \mathrm{P}<0.01$; $* * * \mathrm{P}<0.001$.

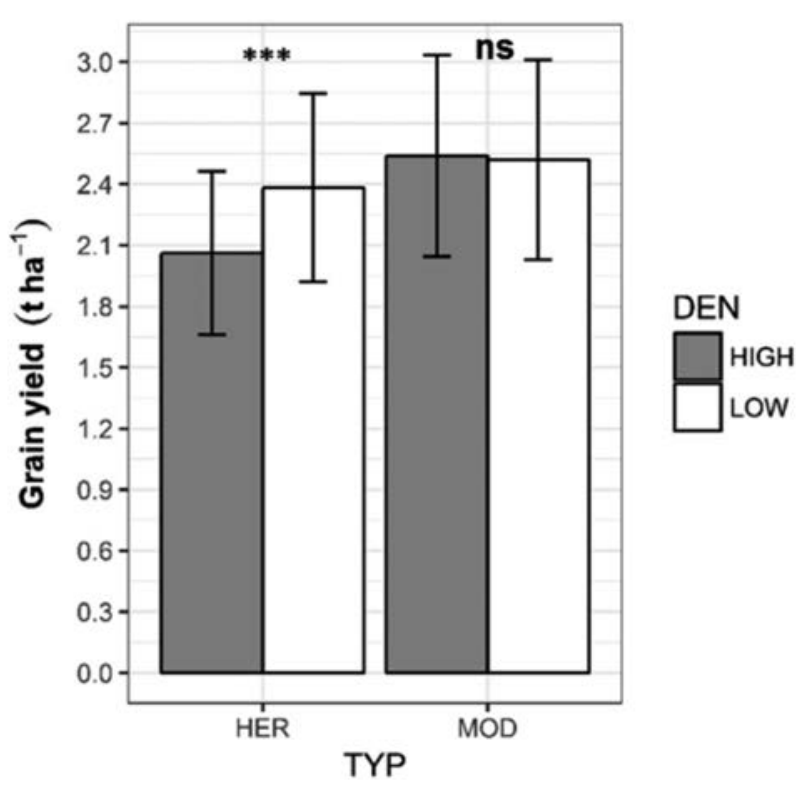

Figure 1. Predicted marginal means for grain yield. Significance of the factor sowing density (DEN) within each type of cultivar (TYP) is reported on the graph. HER, heritage cultivars; MOD, modern cultivars. Bars are standard errors of the means as calculated by $R / l$ smeans on the retained model for grain yield. ${ }_{* * *} \mathbf{P}<0.001$; ns, non significant. 
In our experiment, the thousand-kernel weight was not influenced by diversity of the crop stand. Heritage cultivars had higher thousand-kernel weight compared to modern cultivars $(\mathrm{P}=0.01)$. In the heritage cultivars the thousand-kernel weight was $5.5 \%$ lower at high density $(\mathrm{P}=0.009)$.

The percentage of plant lodging was studied only in the heritage cultivars in order to test for the effect of sowing density and crop stand diversity. Modern cultivars were not included in this analysis because they never showed any lodging. In heritage cultivars, plant lodging decreased from $32.3 \pm 5.1 \%$ at high density to $10.8 \pm 11.1 \%$ at low density.

Table 8. Likelihood ratio test for fixed factors and interactions in the retained model for seeds spike $\mathrm{e}^{-1}$ and fertile spikelets spike $\mathrm{e}^{-1}$.

\begin{tabular}{lccc} 
& Factor & $\chi^{2}$ & P \\
Seeds spike & & & \\
& DEN & 118.76 & $0.000^{* * *}$ \\
& DIV & 0.02 & $0.89(\mathrm{~ns})$ \\
Fertile spikelets spike $^{-1}$ & DEN:DIV & 7.00 & $0.008^{* *}$ \\
& DEN & 10.80 & $0.001^{* *}$ \\
\hline
\end{tabular}

DEN, sowing density; DIV, crop stand diversity; DEN:DIV, interaction sowing density to crop stand diversity. ${ }^{* *} \mathrm{P}<0.01 ;{ }^{* * *} \mathrm{P}<0.001 ;$ ns, not significant.

Table 9. Likelihood ratio test for fixed factors and interactions in the retained model for weed biomass at harvest.

\begin{tabular}{lcc} 
Factor & $\chi^{2}$ & $\mathrm{P}$ \\
DEN & 8.98 & $0.003^{* *}$ \\
TYP & 11.41 & $0.007^{* * *}$ \\
\hline
\end{tabular}

DEN, sowing density; TYP, type of cultivars. ${ }^{* *} \mathrm{P}<0.01 ;{ }^{* *} \mathrm{P}<0.001$.

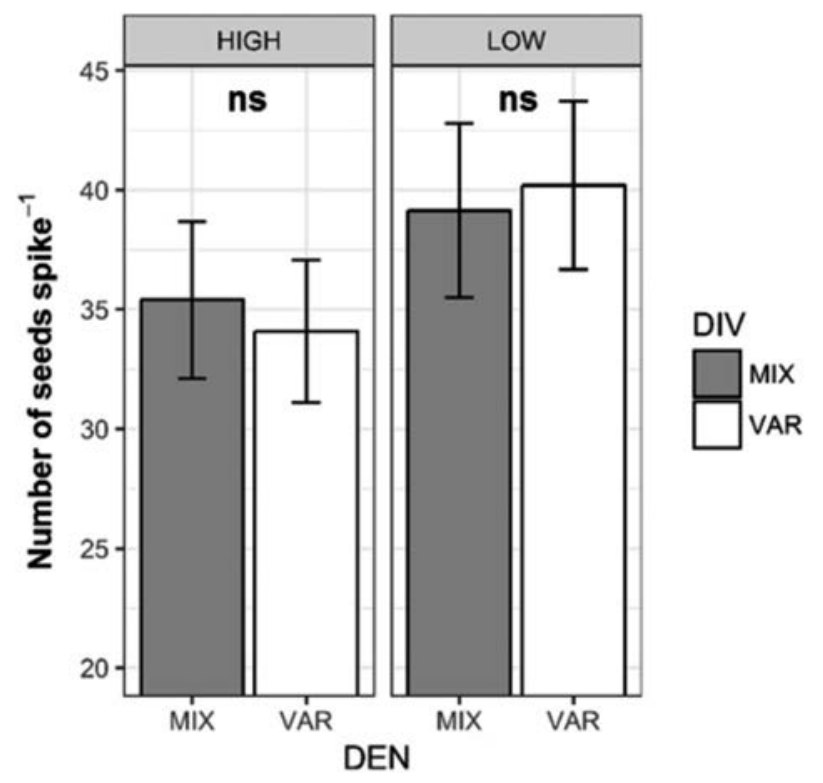

Figure 2. Predicted marginal means for number of seeds spike ${ }^{-1}$. Significance of the factor crop stand diversity (DIV) within each sowing density (DEN) is reported on the graph. DEN, sowing density (LOW, low density; HIGH, high density); DIV, crop stand diversity (VAR, single cultivar; MIX, cultivar mixture). Bars are standard errors of the means as calculated by $R / 1$ smeans on the retained model for number of seeds spike ${ }^{-1}$. ns, not significant.

\section{Traits related to wheat competitive ability against} weeds

Weed biomass was not affected by any of the three factors under study on the first two sampling dates $(5.16 \pm 0.55$ and $7.83 \pm 0.59 \mathrm{~g}$ $\mathrm{m}^{-2}$ in average), whereas significant differences emerged at harvest (Table 9). Weed biomass was on average $46 \%$ higher at low density (10.29 $\pm 1.90 v s 7.04 \pm 1.39 \mathrm{~g} \mathrm{~m}^{-2}$ at high density) (Figure 4). On average, weed biomass was $56 \%$ lower in the heritage cultivars $\left(5.64 \pm 1.23\right.$ vs $12.85 \pm 2.77 \mathrm{~g} \mathrm{~m}^{-2}$ in the modern cultivars) (Figure

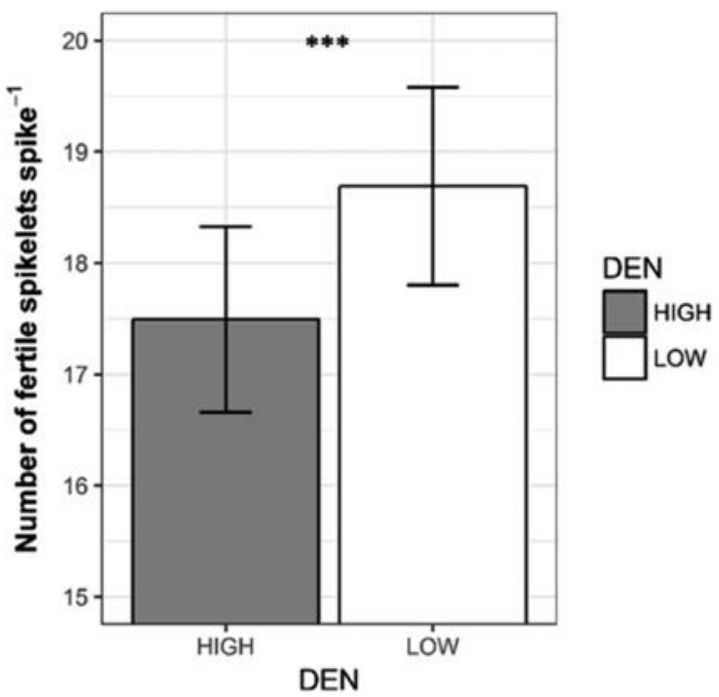

Figure 3. Predicted marginal means for number of spikelets spike ${ }^{-1}$. DEN, sowing density (LOW, low density; HIGH, high density). Bars are standard errors of the means as calculated by $\mathrm{R} / \mathrm{lsmeans}$ on the retained model for number of fertile spikelets spike $^{-1}$. *** $\mathbf{P}<0.001$.

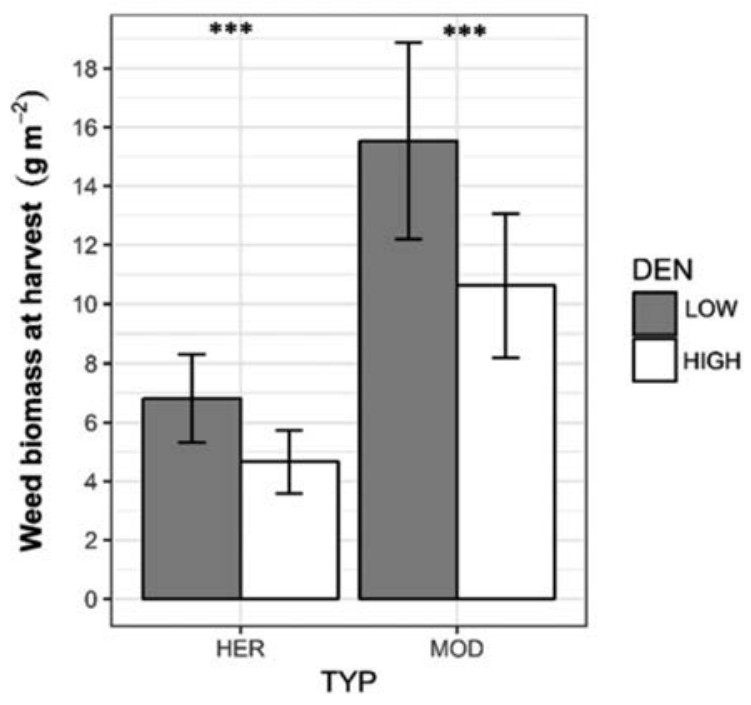

Figure 4. Predicted marginal means for weed biomass at harvest. Significance of the factor sowing density (DEN) within each type of cultivars (TYP) is reported on the graph. LOW, low density; HIGH, high density; HER, heritage cultivar(s); MOD, modern cultivar(s). Bars are standard errors of the means as calculated by $\mathrm{R} / \mathrm{lsm}$ eans on the retained model for weed biomass at harvest. $* * * \mathbf{P}<0.001$. 
4). Total aboveground wheat biomass was not influenced by sowing density at the first two sampling dates (237.75 \pm 8.63 , $859.6 \pm 30.95)$. At harvest, wheat straw was higher at high density $(620.25 \pm 149.67$ vs $553.13 \pm 149.67$ at low density). Plant height was unaffected by sowing density. As expected, plant height was largely higher $(86 \%)$ in heritage cultivars $(135.6 \pm 2.8 \mathrm{~cm} \mathrm{vs}$ $73.1 \pm 2.8 \mathrm{~cm}$ in modern cultivars). The LAI measured in May and June was $24 \%$ and $14 \%$ lower at low than at high density respectively (1.49 \pm 0.61 vs $1.96 \pm 0.61$ in May and $2.02 \pm 1.02$ vs $2.35 \pm 1.02$ in June). In June, LAI was $59.2 \%$ higher in heritage than in modern cultivars $(2.69 \pm 1.02$ vs $1.69 \pm 1.02)$.

\section{Discussion}

Low sowing density of 250 viable seeds $\mathrm{m}^{-2}, 37.5 \%$ less than the local standard density of 400 viable seeds $\mathrm{m}^{-2}$, affected crop stand development all over both growing seasons. Thanks to the well known plasticity of grain yield, the production did not decrease at moderate lower sowing density of our experiment as it was also observed in previous studies (Faris and De Pauw, 1980; Freeze and Bacon, 1990; Puckridge and Donald, 1967; Reynolds et al., 1996; Spink et al., 2000). In the case of heritage cultivars, grain yield even increased with sparser crop stand.

This depended partly by a higher number of tillers per plant and a higher survival of such tillers to produce fertile spikes at low density. The increase in number of fertile spikelets per spike was the other powerful yield component adjustment that buffered the production in the modern cultivars and increased it in the heritage cultivars. This effect was coupled with the increase in the number of seeds per spike. An increase in the values of this parameter to counterbalance the lower number of spikes $\mathrm{m}^{-2}$ is in accordance with previous studies on the effect of sowing density in wheat (Bustos et al., 2013; Li et al., 2016).

No significant effect of density was detected in terms of thousand-kernel weight for modern cultivars. In the heritage cultivars, the thousand-kernel weight was only $5.5 \%$ lower at high density. The increase in seeds per spike was mainly determined by the higher fertility of the basal spikelets, otherwise sterile. The increased fertility of basal spikelets (Li et al., 2016), together with higher lodging at high density for heritage cultivars, may explain the results in terms of higher thousand-kernel weight at low density for heritage cultivars.

Due to the effects detected on number of tillers/spikes per plant, number of seeds per spike and thousand-kernel weight, grain yield did not decrease significantly or even increased at low density. However, the weed pressure at low sowing density was stronger both in heritage and modern cultivars. The increase of weed biomass was coupled with the decrease of soil cover at low density. This effect was evident for both types of cultivars. Still, at low density weed biomass in heritage cultivars was lower than that of modern cultivars. Weed infestation in the two years was rather low (maximum weed biomass at harvest: $12.85 \pm 2.77 \mathrm{~g} \mathrm{~m}^{-2}$ in modern cultivars). As a consequence, despite our results on weed biomass at harvest were statistically robust, conclusions on the effects of sowing density and cultivar type on weed suppression should be drawn with caution because these effects would need to be confirmed in situations characterised by higher weed infestations. Nevertheless, our results are in accordance with previous studies that showed a higher suppressive ability by heritage cultivars (Lemerle et al., 1996; Mason and Spaner, 2006) and indicate that this effect can be evident even when the weed pressure is not very high. In our study, lower sowing density decreased crop lodging in the heritage cultivars. Our results show a non-influential effect of crop stand diversity on the response to low sowing density. This result may be due to the type of cultivar mixtures tested. The main differences ascribed to sowing density in our experiment are due to the type of cultivar (modern vs heritage) but the two mixtures tested are homogeneous for this factor because the cultivars of the two types were not mixed in order to keep a uniform end-use quality. Our results show that, even if this strategy might be suitable for exploiting some benefits of functional biodiversity (e.g. resistance to leaf diseases) this is not the case for all agroecosystem services of interest. Choosing the right level of wheat trait heterogeneity in planning diverse crop stands remains a challenge for expanding the use of cultivar mixtures.

\section{Conclusions}

Our results indicate as well that the practice of reducing wheat stand density where heritage cultivars are used could instead be appropriate under organic and low-input conditions, also thanks to the considerable reduction in crop lodging.

Given the effects detected on yield and weed biomass for the type of cultivar, our study indicates that lower sowing density might not be appropriate in organic or low-input agriculture where modern cultivars are used because of the increase in weed pressure. Even if in our case this did not turn into a significant reduction in grain yield, likely also because of the relatively low weed infestation level, systematic application of this strategy seems not advisable even in the best weed management conditions because it would increase the weed seedbank, a risky outcome in systems where herbicides cannot be used.

\section{References}

Andrew IKS, Storkey J, 2016. Using simulation models to investigate the cumulative effects of sowing rate, sowing date and cultivar choice on weed competition. Crop Prot. 95:109-15.

Andrew IKS, Storkey J, Sparkes DL, 2015. A review of the potential for competitive cereal cultivars as a tool in integrated weed management. Weed Res. 55:239-48.

Barton K, 2016. MuMIn: Multi-Model Inference. Available from: https://CRAN.R-project.org/package=MuMIn

Bates D, Mächler M, Bolker B, Walker S, 2015. Fitting linear mixed-effects models using lme4. J. Stat. Softw. 67:1-48.

Beavers RL, Hammermeister AM, Frick B, Astatkie T, Martin RC, 2008. Spring wheat yield response to variable seeding rates in organic farming systems at different fertility regimes. Can. J. Plant. Sci. 88:43-52.

Beres BL, Turkington TK, Kutcher HR, Irvine B, Johnson EN, O’Donovan JT, Harker KN, Holzapfel CB, Mohr R, Peng G, Spaner DM, 2016. Winter wheat cropping system response to seed treatments, seed size, and sowing density. Agron. J. 108:1101-11.

Bradshaw AD, 1965. Evolutionary significance of phenotypic plasticity in plants. In: E.W. Caspari and J.M. Thoday (eds.). Advances in genetics. Elsevier, Amsterdam, The Netherlands, pp. 115-55.

Bustos DV, Hasan AK, Reynolds MP, Calderini DF, 2013. Combining high grain number and weight through a DH-pop- 
ulation to improve grain yield potential of wheat in high-yielding environments. Field Crop Res. 145:106-15.

Doll H, Holm U, Søsgaard B, 1995. Effect of crop density on competition by wheat and barley with Agrostemma githago and other weeds. Weed Res. 35:391-6.

Fang Y, Liu L, Xu B-C, Li F-M, 2011. The relationship between competitive ability and yield stability in an old and a modern winter wheat cultivar. Plant Soil. 347:7-23.

Faris DG, De Pauw, RM, 1980. Effect of seeding rate on growth and yield of three spring wheat cultivars. Field Crop Res. 3:289-301.

Freeze DM, Bacon RK, 1990. Row-Spacing and Seeding-Rate Effects on Wheat Yields in the Mid-South. J. Prod. Agric. $3: 345-8$.

Hoad SP, Bertholdsson N-Ø, Neuhoff D, Köpke U, 2012. Approaches to breed for improved weed suppression in organically grown cereals. In: E.T. Lammerts van Bueren, J.R. Myers (eds.) Organic crop breeding. Wiley-Blackwell, New York, NY, USA, pp. 61-76.

Kaut AHEE, Mason HE, Navabi A, O’Donovan JT, Spaner D, 2009. Performance and stability of performance of spring wheat variety mixtures in organic and conventional management systems in western Canada. J. Agr. Sci. 147:141-53.

Korres NE, Froud-Williams RJ, 2002. Effects of winter wheat cultivars and seed rate on the biological characteristics of naturally occurring weed flora. Weed Res. 42:417-28.

Kristensen L, Olsen J, Weiner J, 2008. Crop density, sowing pattern, and nitrogen fertilization effects on weed suppression and yield in spring wheat. Weed Sci. 56:97-102.

Kuznetsova A, Brockhoff PB, Christensen RHB, 2016. lmerTest: tests in linear mixed effects models. Available from: https://CRAN.R-project.org/package=lmerTest

Lemerle D, Verbeek B, Cousens RD, Coombes NE, 1996. The potential for selecting wheat varieties strongly competitive against weeds. Weed Res. 36:505-13.

Lenth RV, 2016. Least-squares means: The R package lsmeans. J. Stat. Softw. 69:1-33.

Li Y, Cui Z, Ni Y, Zheng M, Yang D, Jin M, Chen J, Wang Z, Yin J, 2016. Plant density effect on grain number and weight of two winter wheat cultivars at different spikelet and grain positions.
Plos One 11:e0155351

Mason H, Navabi A, Frick B, O’Donovan J, Spaner D, 2007. Cultivar and seeding rate effects on the competitive ability of spring cereals grown under organic production in Northern Canada. Agron. J. 99:1199-207.

Mason HE, Spaner D, 2006. Competitive ability of wheat in conventional and organic management systems: a review of the literature. Can. J. Plant Sci. 86:333-43.

Meier U, Bleiholder H, Buhr L, Feller C, Hack H, Hess M, Lancashire PD, Schnock U, Stauss R, Van Den Boom T, Weber E, Zwerger P, 2009. The BBCH system to coding the phenological growth stages of plants-history and publications. J. Für Kult. 61:41-52.

Olsen J, Kristensen L, Weiner J, 2006. Influence of sowing density and spatial pattern of spring wheat (Triticum aestivum) on the suppression of different weed species. Weed Biol. Manag. 6:165-73

Puckridge DW, Donald CM, 1967. Competition among wheat plants sown at a wide range of densities. Crop Pasture Sci. 18:193-211.

R Core Team, 2016. R: A language and environment for statistical. R found. Stat. Comput. Available from: http://www.R-project.org/

Reynolds MP, Rajaram S, McNab A, 1996. Increasing yield potential in wheat: breaking the barriers: Proceedings of a Workshop Held in Ciudad Obregón, Sonora, Mexico, CIMMYT.

Ruisi P, Frangipane B, Amato G, Frenda AS, Plaia A, Giambalvo D, Saia S, 2015. Nitrogen uptake and nitrogen fertilizer recovery in old and modern wheat genotypes grown in the presence or absence of interspecific competition. Front. Plant Sci. 6:185.

Sadras VO, Reynolds MP, de la Vega AJ, Petrie PR, Robinson R, 2009. Phenotypic plasticity of yield and phenology in wheat, sunflower and grapevine. Field Crop. Res. 110:242-50.

Spink JH, Semere T, Sparkes DL, Whaley JM, Foulkes MJ, Clare RW, Scott RK, 2000. Effect of sowing date on the optimum plant density of winter wheat. Ann. Appl. Biol. 137:179-88.

Whaley JM, Sparkes DL, Foulkes MJ, Spink JH, Semere T, Scott RK, 2000. The physiological response of winter wheat to reductions in plant density. Ann. Appl. Biol. 137:165-77. 